\title{
The Tetrafigap Survey on the long-term outcome of tetraplegic spinal cord injured persons, Part II: Demographic characteristics and initial cause of injury
}

\author{
J-F Ravaud*, ${ }^{*}$, M Delcey ${ }^{2}$, J-F Desert ${ }^{3}$ and the TETRAFIGAP Group $\dagger$ \\ ${ }^{1}$ INSERM (National Institute for Health and Medical Research), IFRH (Federative Research Institute on \\ Disability), Paris, France; ${ }^{2}$ Association des Paralysés de France (APF), Paris, France; ${ }^{3}$ Centre of Neurological \\ Rehabilitation, Coubert, France
}

\begin{abstract}
Objectives: After presenting in part I the protocol and the methodology of the Tetrafigap Survey, this article is aimed at investigating demographic characteristics, initial cause of trauma and spinal injury in the French tetraplegic spinal cord injured (TSCI) population.

Study design: The Tetrafigap Survey is a multicentre epidemiological survey on the outcome of TSCI people following their first admission to a rehabilitation department or centre.

Setting: The survey was conducted with the participation of 35 French-speaking collaborating centres.

Method: A self-administered questionnaire was carried out among consenting TSCI patients followed by the centres. 1668 questionnaires fulfilled all the required criteria for data analysis. Results: The socio-demographic variables (gender, current age and age at the time of accident, duration of disability), circumstances of accident as well as initial spinal cord lesions are reviewed in the body of the text.

Conclusion: The results from this survey form the first detailed description of the French TSCI population. Whereas demographic data show many similarities with those of previous studies in other countries, some specific differences are highlighted, in particular relating to the type of accident.
\end{abstract}

Spinal Cord (2000) 38, 164-172

Keywords: spinal cord injury; tetraplegia; epidemiology; demography; etiology

\section{Introduction}

The TETRAFIGAP survey is a multicentre epidemiological survey concerning the outcome of tetraplegic spinal cord injured (TSCI) people carried out under the aegis of the French-speaking International Association of Paraplegia Leading Groups (AFIGAP). It involved most of the French specialised rehabilitation Centres and Departments as well as some European Frenchspeaking Centres in Belgium and Switzerland. It is aimed at evaluating the medical situation as well as life conditions of TSCI people. The interest concerning this severely injured population is twofold. On the one hand, patients whose neurological level of injury is high have the most extensive problems relating to physical medicine, rehabilitation, and social reintegration. On the other hand, studies have shown that among spinal cord injured (SCI) patients, the proportion of tetraplegics is increasing. ${ }^{1}$

According to major follow-up studies, TSCI patients account for $29 \% \%^{2}$ to $75 \%{ }^{3}$ of SCI patients as a whole; the vast majority of authors indicate a proportion of

*Correspondence: J-F Ravaud, CERMES - INSERM U. 502, 182 Boulevard de la Villette, F 75019, France around $50 \% \pm 12 \% .^{4-8}$ According to the National Cord Injury DataBase, the rate of TSCI patients is close to $55 \% .{ }^{9}$ A French survey of 149 patients by Daverat et al mentions a rate of $52 \%$ TSCI patients at hospitalisation, but this figure is only $47 \%$ among the survivors who could be included in the survey (between 7 and 10 years following the accident). ${ }^{10}$ The most recent French survey gives a rate of $38 \%$ TSCI, but in this case the survey was conducted outside institutions, a fact which is liable to lower the ratio of TSCI patients. ${ }^{11}$ A low rate of TSCI patients $(31 \%)$ is mentioned by Whiteneck et al but this survey involves accidents which occurred before $1970 .{ }^{12}$ Follow-up of the SCI population by DeVivo et al shows a progressive, moderate though steady increase in the proportion of TSCI patients. The last available figure, for the 1984-1986 time period, indicates $57.5 \%$ TSCI patients. ${ }^{13}$ Few studies concerning SCI patients are specifically oriented toward TSCI patients. In addition, inclusion criteria (in particular age range) show noticeable variations. Some surveys would appear to deal with populations recruited using very different options. ${ }^{3}$ Therefore, it may sometimes be difficult to establish firm grounds for making comparisons. 
Several studies have been published in the USA by DeVivo et al. They rely on data collected since 1973 by the National Database on Spinal Cord Injured patients. These authors have investigated the effects of rehabilitation on 13763 SCI patients, of whom $54.2 \%$ were TSCI. $^{4}$ They evaluated the prognostic factors, ${ }^{13}$ the changes in demographic data as well as SCI treatment ${ }^{1}$ and also the causes and costs of spinal cord injuries in the USA. ${ }^{14}$ McColl et al analyzed the long-term survival, the life conditions and the medical complications of 606 SCI patients, of whom $44.2 \%$ were TSCI patients.

The US studies carried out by DeVivo et al ${ }^{1,4,13}$ (and a further study in Japan by Shingu et $a l^{3}$ ) are among the largest studies which have included tetraplegics, with 7460 and 7317 TSCI patients, respectively. No European survey could reach such sizes. The main reference surveys, which were carried out in the United Kingdom as well as in Denmark or in Sweden, provided data concerning the overall SCI patients with much lower sample sizes. Whiteneck et al and Frankel et $a l^{2,12}$ carried out their work on mortality and long-term outcome of SCI patients, of whom $31 \%$ were TSCI, ${ }^{12}$ from files of the two main British specialised rehabilitation centres (834 and 3179 subjects, respectively), providing in this case results used as a bench mark for life expectancy and mortality. Biering-Sorensen et $a l^{15}$ and Hartkopp et $a l^{8}$ analyzed the SCI population in Denmark and the longterm outcome of 268 and 888 SCI patients, respectively, the latter study including a rate of $47.7 \%$ TSCI patients. Levi et al conducted the Stockholm SCI Study in Sweden. ${ }^{6}$ This epidemiological study on the outcome of 353 SCI subjects included $41 \%$ TSCI patients.

In France, Minaire et al investigated the survival and causes of death of 843 SCI patients (including 142 TSCI patients) at 10 year follow-up. ${ }^{16}$ Daverat et al studied 188 consecutive SCI patients hospitalised between 1982 and 1985, of whom 149 survivors (99 TSCI patients) were subjected to a subsequent survey. ${ }^{17}$ In particular, this survey emphasised initial prognostic factors relating to functional independence and quality of life. ${ }^{17}$ Recently, Barbin and co-workers interviewed 291 SCI patients (of whom $37.6 \%$ were TSCI) living at home. The main issues they addressed were their life conditions and medical follow-up. ${ }^{11}$

The current paper is aimed at describing the major demographic characteristics of the French TSCI population as well as causes of the initial accident and spinal injury. The above literature review reveals that very few studies are conducted on tetraplegics alone. It was only possible to establish comparisons with the main international studies involving SCI when they could provide specific data on this sub-population.

\section{Method}

In an initial publication (part I), the precise methodology employed in this research and the results of the census phase of the Tetrafigap Survey have been described. ${ }^{18}$ They can be summarised as follows:
The criteria used for inclusion in the study were:

(1) A complete or incomplete, including postsurgical, traumatic cervical cord lesion

(2) Age 16 or over at the time of the accident

(3) Accident which occurred more than 2 years ago

(4) All subjects were adults at the time of the survey.

The enquiry consisted of a self-administered questionnaire covering the following topics: the situation at the time of the accident, the medical evolution between the accident and the end of stay in a rehabilitation unit, the evolution after discharge and the current situation (medical, social, professional and personal).

The survey was carried out in 1995/96 thanks to the cooperation of 35 specialised Rehabilitation Centres (33 in France, one in Belgium, one in Switzerland). In a first step, these collaborating centres identified 6082 TSCI patients. After excluding 769 double entries and the 603 known deaths, 4710 people were then sent a letter asking for their informed consent to participate in the survey. Two thousand two hundred and fifty one people gave their consent and received a questionnaire. One thousand eight hundred and thirty questionnaires were sent back (ie a response rate of $77 \%$ ) of which 1668 questionnaires fulfilled all the necessary criteria for data analysis. These questionnaires are those on which the following analyses are based; they constitute the final population group of the Tetrafigap survey.

The survey population (1668 subjects who answered) and the 4710 persons registered (TSCI assumed alive) were compared with respect to gender and age. While there was no difference in sex ratio between the persons contacted and those who answered, the persons who gave their consent were younger (on average 43.5 years) than those who refused to participate in the survey (48.7 years) and those lost for follow-up (51.4 years). These results match those of Krause who also found a lower mean age for subjects participating in his study than those who did not. ${ }^{19}$ The mean age of the 1668 persons who answered the survey (43.6 years) is, however, similar to that of the 2251 subjects who had agreed in principle (43.5 years).

\section{Results}

\section{Demographic data}

Current age At the time of the survey, the population's mean age is $43.6 \pm 13.5$ years* (median :

\footnotetext{
*There are some slight discrepancies between results in Tables and in the body of the text. They are due to different frequency counts because of non responses, which differ according to the variables. Though the sample size is 1668, the total is for instance 1656 in Table 2 or 1521 in Table 3
} 
41.6 years) with a minimum of 20 and a maximum of 88 years. The age distribution of the Tetrafigap survey is displayed in Figure 1.

Sex ratio For this population, the overall male/female ratio is $4 / 1$ ( $79.9 \%$ males $)$. This ratio is high for all age groups, but steadily decreases after 30 years. The rate for women is higher for the older subjects, in particular those over 50, than for the younger ones (before 40 years) $(P<0.01)$. These data are outlined in Table 1. Similarly, TSCI women are significantly $(P<0.001)$ older than men $(46.0$ years \pm 14.3 versus $43.0 \pm 13.3)$.

Age at the time of accident The mean age at the time of accident is $30.7 \pm 13.2$ years. The median ( 25.9 years) reflects the influence of accidents earlier in life on age distribution (Figure 2). Sixty per cent of accidents involved subjects under 30 and three-quarters of them occur before 40 years of age. The extremes of age at the time of accident are 16 and 78 years. Current age and age at the time of accident are linked $(r=0.83$, $P<0.001)$ : on average, the oldest subjects at the time of the survey had their accident later (in fact there are few accidents distant in time). The rate for men is higher when the accident occurs at a young age $(P<0.01)$. When the accident occurs before 25 years, the male/female ratio is $4: 8$; it is half this $(2: 4)$ after 55 years. About $30 \%$ of late accidents (after 50 years) involve women versus a sixth for the earliest. Consequently, the mean age of accident is significantly higher for women $(33.5 \pm 14.4)$ than for men $(30.0 \pm 12.8)(P<0.001)$.
Time elapsed since the accident The mean duration of disability (time elapsed since the accident) is 12.9 years (median 11.2 years) with extremes ranging from 3 to 50.4 years (accident which occurred in 1945). Therefore, $45 \%$ of accidents date back less than 10 years, $23 \%$ date back 10 to 14 years, the same proportion $(23 \%) 15$ to 24 years and $9 \%$ date back 25 years or more (Figure 3). These results depend mostly on the inclusion criteria used for each survey population (in particular, the presence or absence of a minimum delay between the accident and the survey), but they put our survey population in perspective with respect to other survey populations. Thus, these figures are not really comparable, even with studies on long-term outcome. $^{7,12}$ The mean duration of disability for men does not differ significantly from that for women $(13.0$ versus 12.4 years).

Table 1 Sex ratio by age groups

\begin{tabular}{lcccccc}
\hline \multicolumn{7}{c}{ Age (years) } \\
Gender & $20-29$ & $30-39$ & $40-49$ & $50-59$ & and over & Total \\
\hline Males & & & & & & \\
$\quad n$ & 220 & 420 & 320 & 205 & 163 & 1328 \\
$\quad \%$ & 81.8 & 84.3 & 79.6 & 75.1 & 74.1 & 79.9 \\
Females & & & & & & \\
$\quad n$ & 49 & 78 & 82 & 68 & 57 & 334 \\
$\quad \%$ & 18.2 & 15.7 & 20.4 & 24.9 & 25.9 & 20.1 \\
Sex ratio & 4.5 & 5.4 & 3.9 & 3.0 & 2.9 & 4.0 \\
$\quad(\mathrm{M} / \mathrm{F})$ & & & & & & \\
\hline
\end{tabular}

percentages

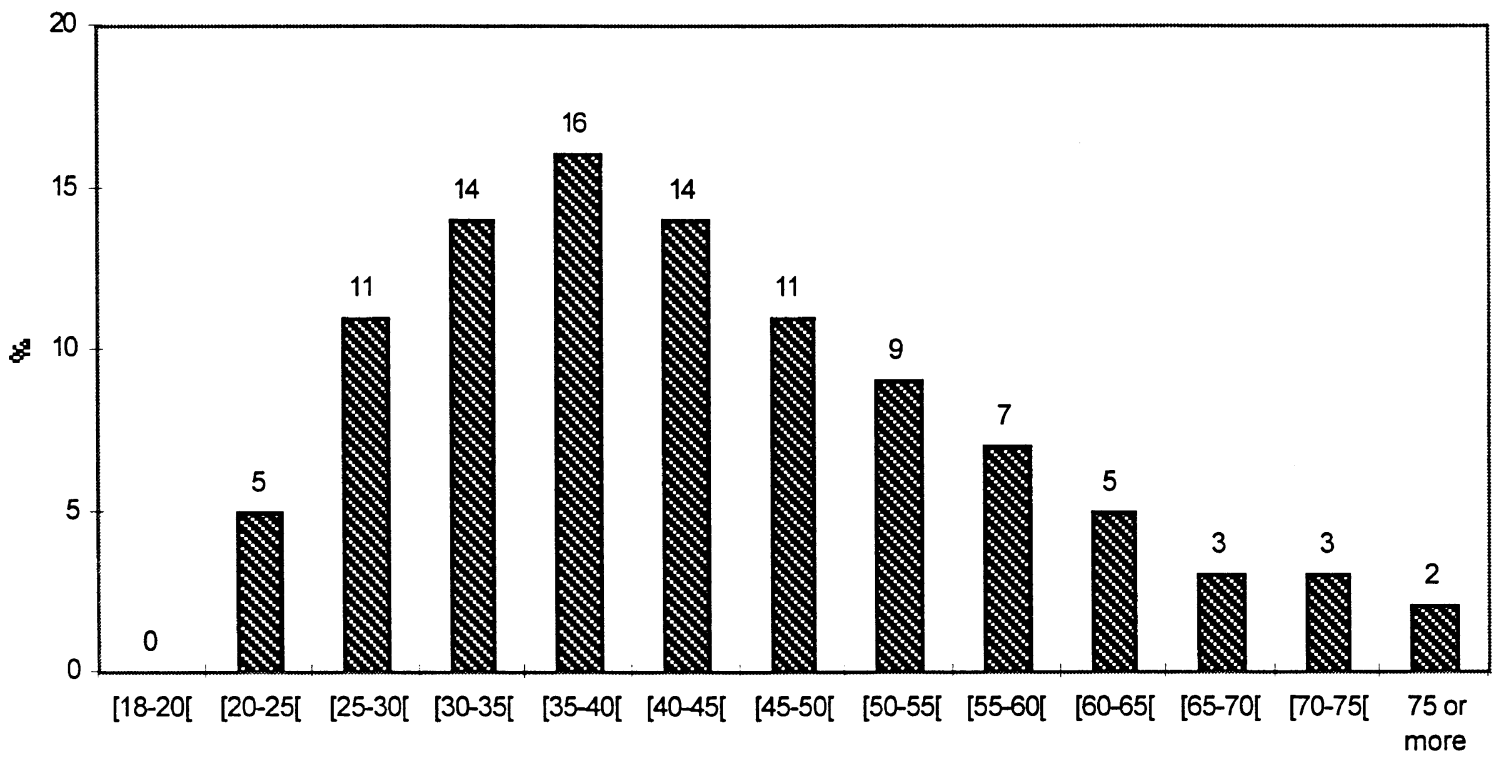

years of age

Figure 1 The Tetrafigap sample age group distribution at the time of survey $(n=1668)$ 
Initial circumstances

The survey made it possible to accurately analyze the causes of accidents (Table 2). The most prevalent cause of accident involved is traffic accident $(57.9 \%)$ followed by sports and leisure $(15.8 \%)$. Diving accidents have been separated because of their high rate $(6.5 \%)$.
Links between the type of accident and other factors have been examined:

- Age $(P<0.001)$ : the youngest subjects (under 30 years) have a high rate of traffic accidents (TA) $(60.3 \%)$ and, more specially, sport/diving accidents

percentages

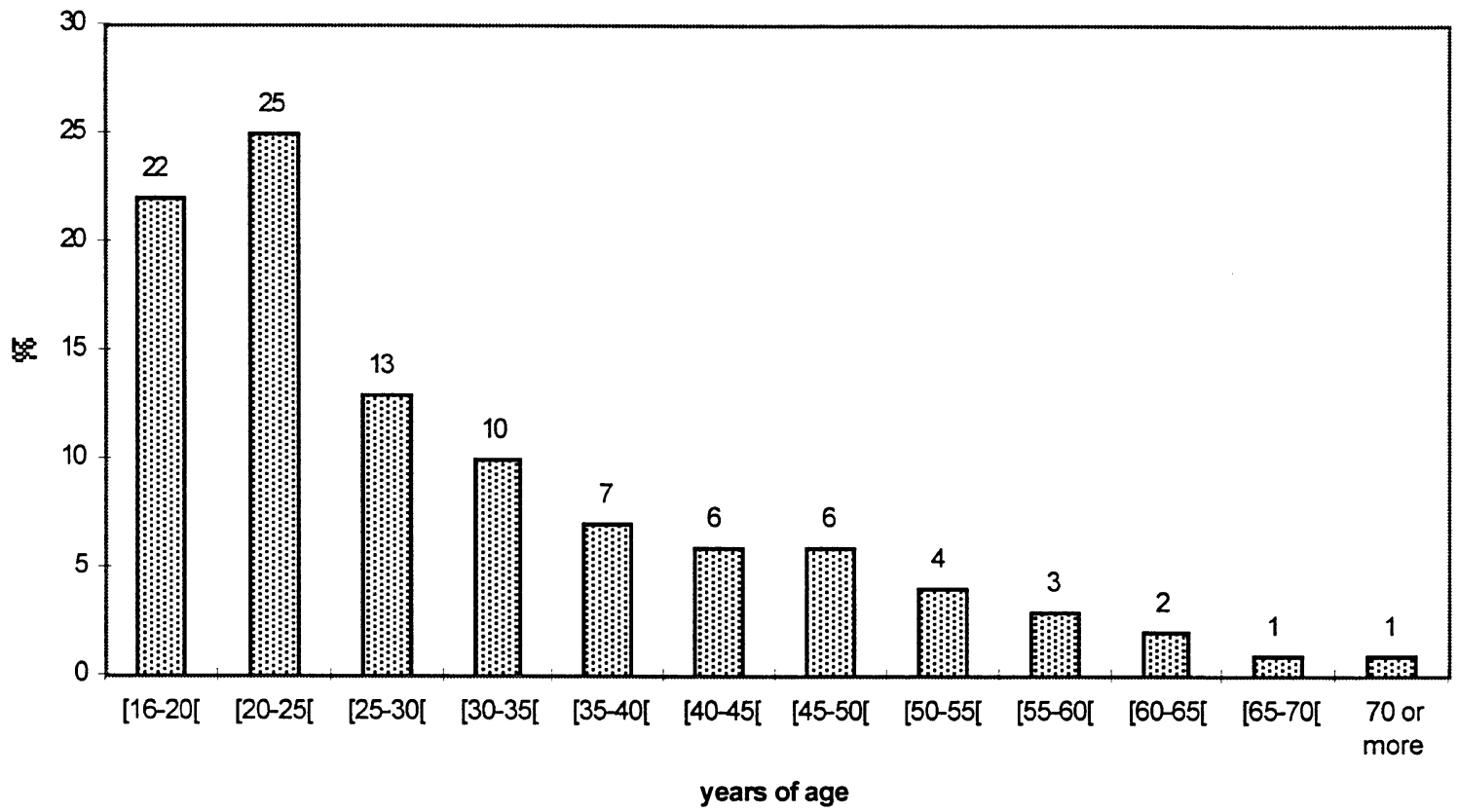

Figure 2 Distribution by age group at the time of accident

percentages

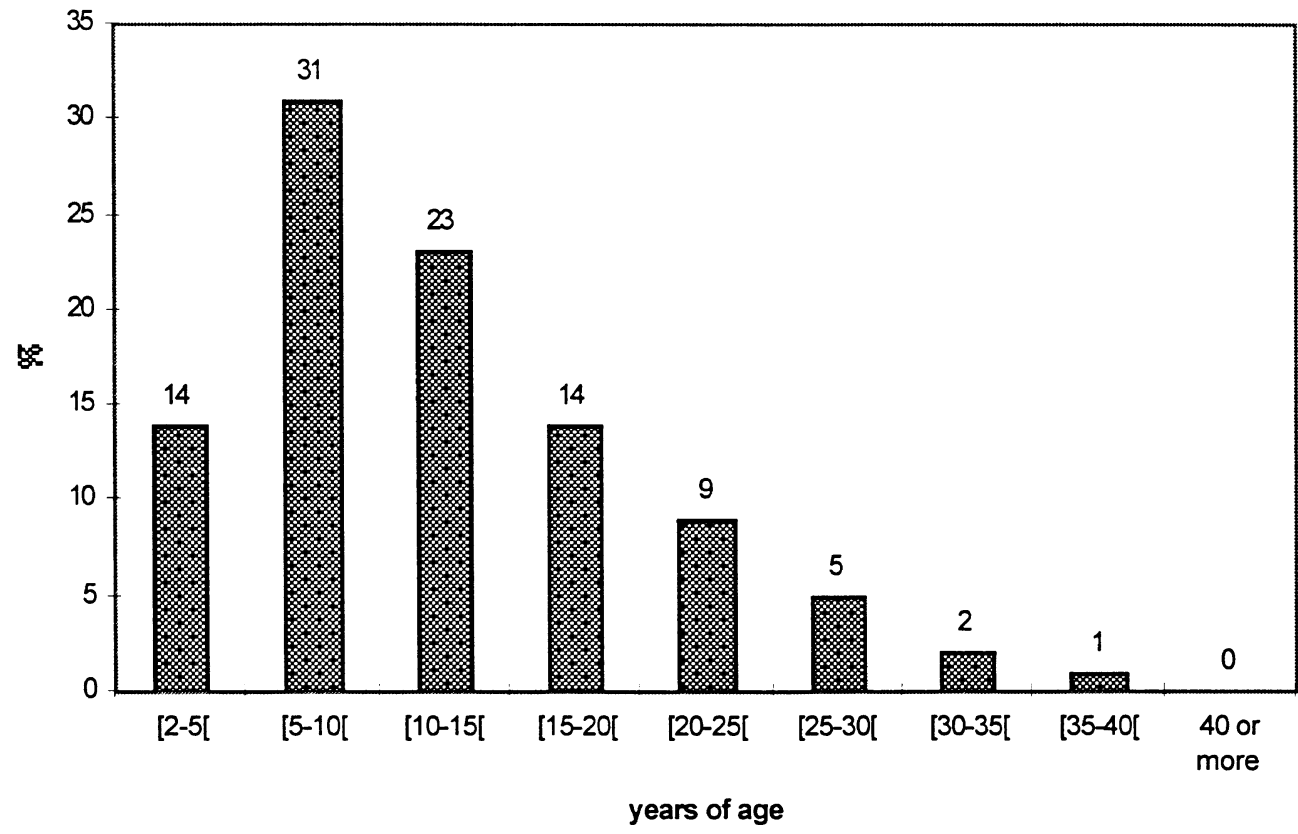

Figure 3 Distribution as a function of time elapsed since the accident $(n=1668)$ 
Table 2 Type of accidents according to demographic variables and type of injury

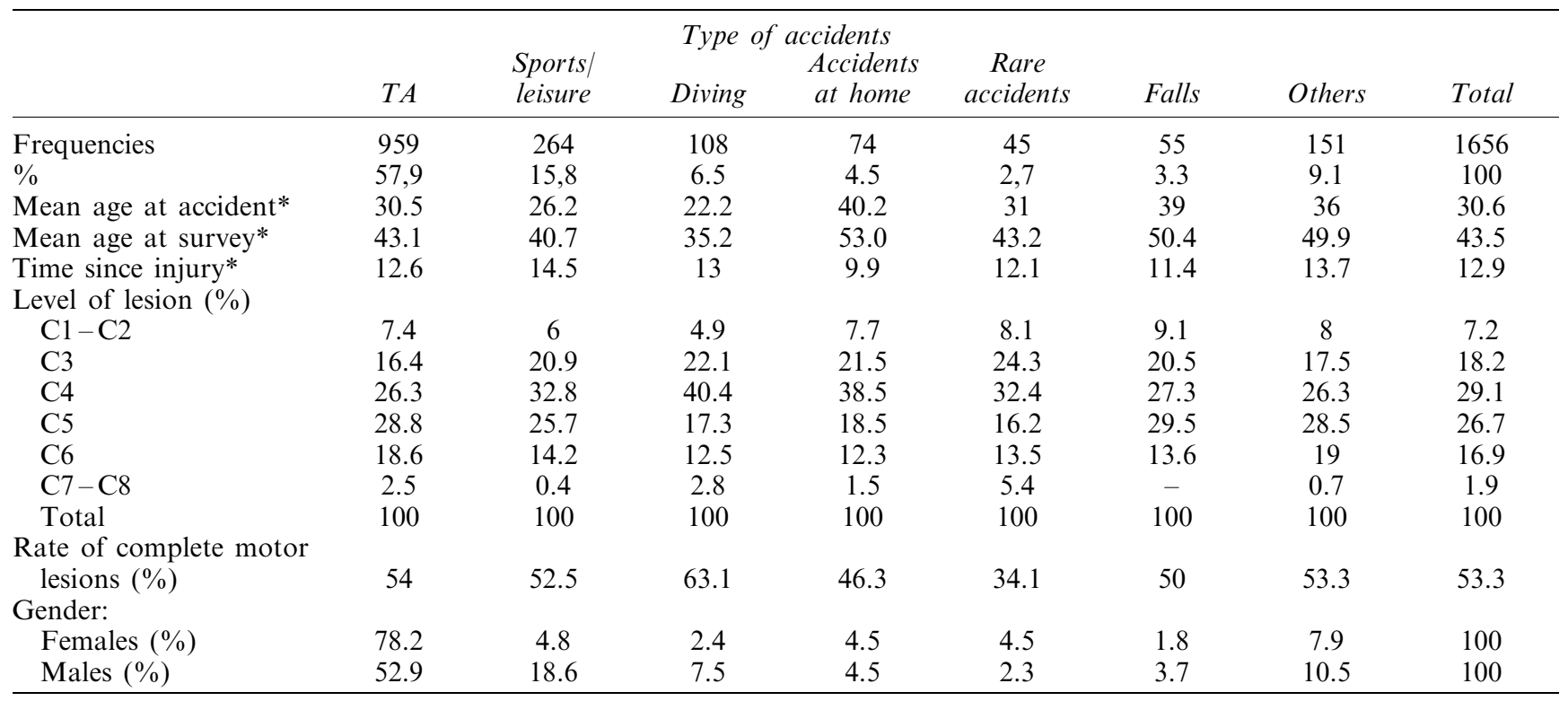

*In years; TA: traffic accidents; Rare accidents: war, assaults, suicide attempt, surgical accidents

(32.2\%). Diving accidents account for $15 \%$ of accidents before 30 years and decrease quickly afterwards $(7.3 \%$ after $30,5 \%$ after $40,3 \%$ after 50 , etc. . .). Age at the time of accident seems to be the decisive factor ( $c f$. below). Persons aged over 60 years at the time of the survey, whose accident occurred at an average older age, differed from other age groups because of a higher rate of accidents at home and falls.

- Age at the occurrence of accident $(P<0.001)$ : the differences involve all types of accidents with the exception of TA whose rate shows few variations (from $52 \%$ to $62.6 \%$ ) from one age group to another. Accidents at home steadily increase with age at the time of accident (up to $19.1 \%$ after 55 years), sport/leisure accidents account for one accident in five before 30 years and then they decrease progressively. Diving accidents are more prevalent in those of young age at the time of accident: $15.7 \%$ of accidents before 20 years, about $5 \%$ between 20 and 35 years, $2 \%$ or less afterwards. Conversely, falls are very infrequent before 35 years but they account for $6 \%$ to $7.5 \%$ of accidents in all age groups afterwards. Finally, the other accidents (almost all accidents at work) account for the third largest cause of accidents, but are the second largest cause after 45 years of age.

- Length of time after the accident $(P<0.01)$. Differences are low: TA are somewhat more frequent since 1975 - but they already represented the majority of accidents $(53.5 \%)$ before -, sport/ leisure/diving accidents were proportionally more frequent before 1975 (28.8\% versus $21 \%)$. However, one must take into consideration the fact that survival regarding the type of accident may be different.

- Gender: here there are major differences. The only category which does not separate men and women is that of accidents at home ( $4.5 \%$ for each sex). Women are proportionally much more often involved in TA than men are $(78.2 \%$ versus $52.9 \%$ ). Conversely, the incidence of sport/leisure/ diving accidents is three times greater in men than in women; so are the 'other' accidents which are mainly accidents at work; falls are also twice as frequent in men.

- Level of neurological lesion: There is no significant link between the type of accident and the level of lesion reported by TSCI patients.

- Furthermore, the link between the type of accident and whether the resultant injury is a complete or incomplete motor lesion just fails to reach significance $(P=0.06)$. There is no link with the complete sensory characteristic of the lesion. However, two types of accidents differentiate themselves noticeably from the others: diving accidents $(63.1 \%$ of complete motor lesions) and, conversely, rare accidents (suicide attempt, war, assault, surgical accidents) where only one third of complete motor lesions are found $(34.1 \%)$ (but only concerning 45 cases). This is to be compared with the role played by age in the complete or incomplete character of the lesion ( $c f$. below).

\section{Cervical cord injury}

The level of injury (Figure 4) is that reported in the questionnaire by the TSCI patients. The most 
frequently reported levels of injury are C4 and then $\mathrm{C} 5$, which both account for more than half the spinal cord injuries of the tetraplegics in this survey.

The level of injury is not significantly linked to gender of TSCI patients, while this is the case with the age of subjects at the time of accident : the higher the level of injury, the higher the mean age at accident (32.9 years for $\mathrm{C} 1-\mathrm{C} 2$ versus 26.7 for $\mathrm{C} 7-\mathrm{C} 8 ; P=0.04$ ) (Table 3 ).

The initial neurological injury was complete in $75.5 \%$ of cases according to the TSCI patients themselves. Current paralysis (at the time of the survey) is complete under the level of injury for $53.3 \%$ of tetraplegics. The Frankel Index, as it can be calculated, provides the following findings (at the time of survey): A: $47 \%, \mathrm{~B}$ : 9\%, C: $9 \%$, D,E grouped: $34 \%$.

A major point is the link between the level of injury and its complete nature: paralysis is less often complete when the level of injury is higher $(P<0.01)$. However, this link must take into consideration the recruitment modality (retrospective questionnaire study, survival from the beginning of rehabilitation process). It may be possible that a certain number of complete, high level injuries were lost for follow-up.
Finally, one must note the link between the level of injury and current age (45.9 for $\mathrm{C} 1-\mathrm{C} 2$ versus 38.6 for C7-C8; $P<0.01)$.

With regard to the motor completeness of the lesion (Table 4), those with a complete paralysis are younger than those with a non-complete paralysis are $(42.0$ versus 44.6 years; $P<0.001)$. Regarding the age at the time of accident, this result is similar, TSCI people with a complete paralysis being younger (28.6 versus 32.2 years; $P<0.001)$. TSCI people with a complete lesion have a slightly older injury (13.4 versus 12.4 years; $P<0.05)$, whereas one might have thought that the oldest subjects survived because of experiencing lesions that were on average less severe (but they were younger at the time of the accident).

\section{Discussion}

\section{Demographic data}

The mean age (43.6 years) of the Tetrafigap population at the time of the survey is comparable to that of the Swedish SCI population: $42 \pm 14$ years (median: 41

percentages

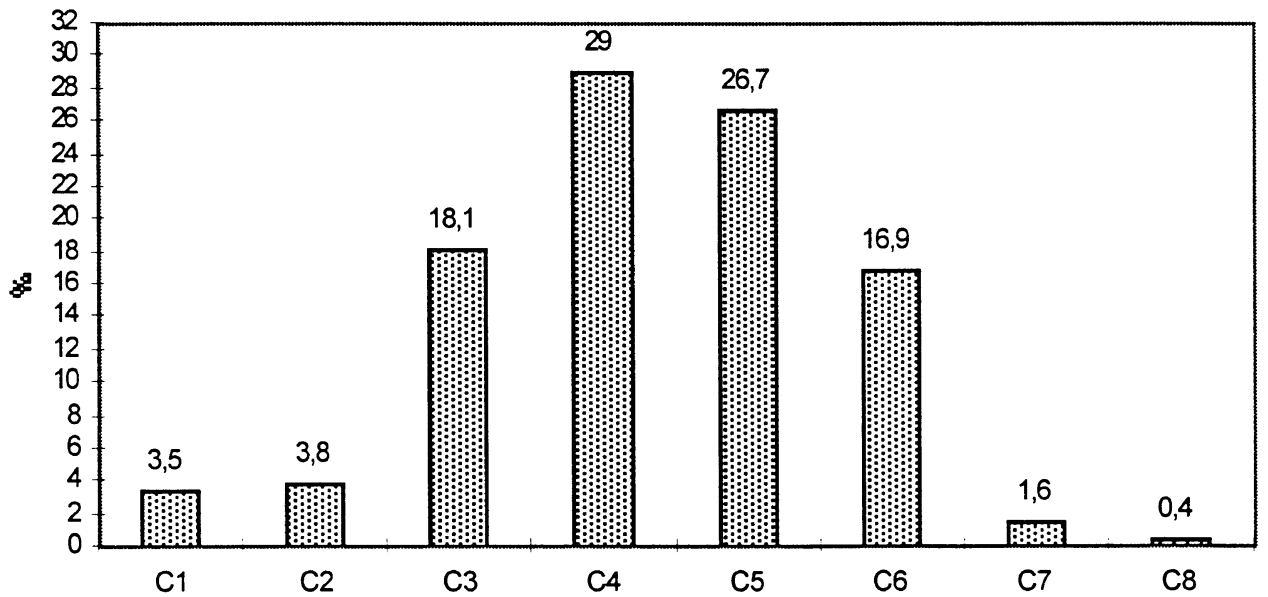

Figure 4 Level of cervical cord injury

Table 3 Level of lesion and demographic variables

\begin{tabular}{|c|c|c|c|c|c|c|c|}
\hline & $C 1-C 2$ & C3 & $C 4$ & $\begin{array}{l}\text { Level of lesion } \\
\qquad 5\end{array}$ & C6 & $C 7-C 8$ & Total \\
\hline Frequencies & 110 & 276 & 442 & 406 & 257 & 30 & 1521 \\
\hline$\%$ & 7.2 & 18.1 & 29.1 & 26.7 & 16.9 & 2.0 & 100 \\
\hline Mean age at accident* & 32.9 & 29.8 & 29.1 & 29.2 & 28.9 & 26.7 & 29.5 \\
\hline Mean age at survey* & 45.9 & 43.5 & 42.2 & 42.4 & 40.9 & 38.6 & 42.5 \\
\hline Time since injury* & 13.0 & 13.6 & 13.1 & 13.2 & 12.0 & 11.9 & 13.0 \\
\hline $\begin{array}{l}\text { Rate of complete motor } \\
\text { lesions }(\%)\end{array}$ & 45.2 & 49.1 & 52.7 & 61.6 & 55.6 & 55.2 & 54.5 \\
\hline Gender: Ratio & & & & & & & \\
\hline Males/Females & 4.0 & 4.7 & 4.1 & 3.5 & 3.9 & 3.3 & 4.0 \\
\hline
\end{tabular}

*In years 
Table 4 Current motor completeness of the lesion and demographic variables

\begin{tabular}{lccc}
\hline & \multicolumn{3}{c}{$\begin{array}{c}\text { Paralysis } \\
\text { Complete }\end{array}$} \\
Incomplete & Total \\
\hline Frequencies & 840 & 737 & 1577 \\
\% & 53.3 & 46.7 & 100 \\
Mean age at accident* & 28.6 & 32.2 & 29.5 \\
Mean age at survey* & 42.0 & 44.6 & 42.5 \\
Time since injury* & 13.4 & 12.4 & 13.0 \\
Gender : Ratio & & & \\
Males/Females & 4.1 & 3.9 & 4.0 \\
\hline
\end{tabular}

*In years

years $)^{6}$ and the French sample by Daverat et al: 41 years. ${ }^{17}$ It falls between series of younger (eg Barbin et al: $34 \pm 11.3$ years ${ }^{11}$ ), or older SCI subjects (McColl et al: $45.6 \pm 11.9$ years ${ }^{7}$ Shingu et al: $48.6 \pm 19.1$ years $\left.^{3}\right)$. However, this age is mostly dependent on inclusion criteria selected for surveys, and which are different in each survey.

The male/female ratio in the present study is $4 / 1$. This finding is identical to those of the other major studies of SCI populations. The male rate is $79.9 \%$, ranging from $77 \%{ }^{15}$ to $87.5 \%,{ }^{12}$ and identical to French authors' results: $80.3 \%$ for Daverat et al. ${ }^{10}$ DeVivo et al observe a male rate of $84.5 \%{ }^{1}$ and the US National SCI Database a male rate of $82.2 \% .^{2}$ A recent French study reveals a more important rate for male, $87 \%$ in TSCI patients versus $77.4 \%$ in SCI patients in general, ${ }^{11}$ a notion that is not emphasised elsewhere. Frankel et $a l^{2}$ show that this male/female ratio no longer varies as a function of time of accident since the mid-1960s, while the oldest survivors in their series are almost only male patients $(3.4 \%$ of females for accidents occurring before 1952). We do not obtain this result since, in our survey, the male/female ratio remains identical, whatever the follow-up time after the accident.

Age differences versus sex are likely to be related to a different mean age at the time of accident, and with the type of accident versus subjects' gender. This result differs from the findings by Levi et al, who do not find significant age differences according to gender, ${ }^{6}$ but it is close to those of Hartkopp et al where the male mean age (27.5 years) is lower than that of females (31 years). ${ }^{8}$

Mean age at the time of accident is similar to that by Levi et al: $31 \pm 14$ years ${ }^{6}$ and DeVivo et al: 31.2 years old in their most recent series (1984-86), a figure that is increasing moderately but steadily since the 1970s (28 years old for the time period 19731977). ${ }^{1}$ Whiteneck et al, whose results are expressed as a function of age groups, display values which are comparable to ours $(69 \%$ of patients injured before 35 years). ${ }^{12}$ Frankel et al reported similar data: $57 \%$ before 30 years of age. ${ }^{2}$ However, all these mentioned studies deal with SCI patients in general and not specifically TSCI.
The increased rate of males in early accidents $(P<0.01)$, which is characteristic of our series, is not observed by Levi et $a l^{6}$ but there are noticeable differences with respect to the causes of accidents in both surveys.

\section{Initial circumstances}

There would appear to be some French specificity with regard to the rate of Traffic Accidents. They account for less than one in two accidents in all other studies: from $43 \%$ to $45 \%$ for Levi et al, ${ }^{6}$ DeVivo et al, ${ }^{1}$ Shingu $e t a l^{3}$ or also for Whiteneck et $a l^{12}$ but $57.9 \%$ in the current study. According to these authors, the second cause of accidents is falls $(20 \%$ to $40 \%$ according to the series). In our series, this cause is less important, while, on the other hand, the proportion of sport/leisure accidents is higher in our survey than any other above-mentioned surveys involving the overall SCI population. These sports accidents, in particular diving accidents, appear therefore to be one of the specificities of the tetraplegic population. This finding is similar to that of Minaire et $a l$, who found in TSCI patients a rate of $19 \%$ for sports accidents (and, 65.8\% of sports accidents had caused tetraplegia). ${ }^{20}$

Conversely, the rate of accidents caused by violent assaults (war, crime, aggression), is noticeably low in our series, in particular with respect to NorthAmerican studies (16\% for DeVivo et al, ${ }^{1} 5 \%$ for Whiteneck et $a l^{12}$ ). However, it must be said that legal regulations, for instance regarding weapons, are very different in these countries.

Our findings about links between gender and type of accident contrast with those of Levi et al, who report a similar proportion of traffic accidents in men $(45 \%)$ and in women $(47 \%){ }^{6}$ Biering-Sørensen et al even reported results which were the converse of ours: women in their study were proportionally less involved $(40 \%)$ by TA than men $(48.5 \%) .{ }^{15}$ On the other hand, this very same study reported the highest rate of sport accidents in men $(6 \%$ versus $3.2 \%)$.

\section{Cervical cord injury}

The injury level (Figure 4) is that reported by the TSCI patients themselves. When several levels were mentioned (most frequently: two levels, for instance $\mathrm{C} 4 / \mathrm{C} 5$ ), the highest level only was taken into account. It is therefore very likely that this has led to our recording an average shifted toward higher levels (predominance of $\mathrm{C} 4$ injuries, which is unusual in the literature data where C5 tetraplegias are predominant). These results will be verified during subsequent clinical surveys.

While caution must be maintained with respect to the reported data outlining neurological lesion level, as far as the accuracy of observed prevalences is concerned, it can be assumed that this does not question the validity of the observed results. 
The rate of complete paralysis is the lowest for the highest lesion levels (Table 3). This result may be attributed to the fact that high-level lesions are more common amongst older subjects whose lesions are more often incomplete.

Surprisingly, a link was observed between the complete nature of injury (initial lesion or aftereffect) and the time elapsed since the accident, but the trend was unexpected: the oldest SCI patients have more often an incomplete lesion while their longer survival would have been in favour of the opposite. In fact, part of the explanation may lie in the fact that the oldest patients were on average much younger at the time of their accident (at that time, the oldest survived to a lesser degree), and the complete nature of injury is linked to a younger age at the time of the accident.

Comparing our findings with data from the literature shows that they match those by Maharaj. ${ }^{21}$ Lin et al reported an even higher proportion of complete lesions $^{22}$ while most of the other series ${ }^{3,6,7,12,15}$ show a majority of incomplete injuries. It is worth noting that the most recent studies ${ }^{21,22}$ are the ones that found the largest number of complete injuries.

The very wide scattering of data at the FRANKEL index from one study to another is striking, the TETRAFIGAP population being very close to the reference survey by DeVivo et al.

\section{Acknowledgements}

$\dagger$ The TETRAFIGAP Survey was carried out with grants from the following organisations which we wish to thank: HANDITEC, the 'Association de Gestion du Fonds pour I'Insertion professionnelle des Personnes Handicapées' (AGEFIPH), the 'Association des Paralysés de France' (APF), the 'Fondation des Mutuelles du Mans - Fondation de France', the 'Fondation Suisse pour la paraplégie', the 'Centre Européen d'Etudes de Sécurité et d'Analyses des Risques' (CEESAR), the 'Institut pour la Recherche sur la Moelle Epinière' (IRME). The authors also wish to thank Papa Abdou (APF) for carrying out statistical analyses, Françoise Marchand (INSERM-IFRH) with her help with translation and the TETRAFIGAP Steering Committee which includes, apart from the authors of this paper, D Boulongne, M Maury, J-P Pédelucq and M Tramblay.

The Tetrafigap survey, carried out under the aegis of the 'Association Francophone Internationale des Groupes d'Animation de la Paraplégie' (AFIGAP), was achieved thanks to the participation of the Tetrafigap group which involves the following 35 associated teams: (1) BerckHôpital franco-américain (Dr Allas); (2) Berck-Centre Hélio-marin (Dr Chikhi); (3) Bichat (Pr Bedoiseau); (4) Bois-Guillaume (Pr Beuret-Blanquart); (5) Bordeaux (Pr Barat, Dr Petit); (6) Bouffémont (Dr Thévenin-Lemoine); (7) Bourbon-Lancy (Drs Malier, Estéve); (8) Bruxelles (Drs Heilporn, Biefnot); (9) Cerbère (Dr Enjalbert, M. Rosebande); (10) Charleville Mézières (Drs Delrez, Skoda); (11) Club de loisirs et d'entraide de Garches; (12) Coubert (Dr Désert); (13) Garches (Prs Bussel et Dizien, Dr LortatJacob et Tramblay); (14) Genève-Hôpital Cantonal Uni- versitaire, (Pr Chantraine, Dr Castagnier); (15) Giens (Drs Boucand et Tournebise); (16) Invalides (INI, Dr Dumurgier, Dr Barouti); (17) Kerpape (Drs Busnel, Cormerais, Pédelucq); (18) La Membrolle sur Choisille (Dr Chauvet); (19) L'Arche (Drs Egon, Isambert); (20) La Tour-deGassies (Dr N'Guyen Van Tam, Dr Wiart); (21) Lay-SaintChristophe (Dr Brugerolle, Dr Thisse); (22) L'HospitaletMontoire (Dr Simon); (23) Limoges (Prs Labrousse et Dudognon, Dr Munoz); (24) Lyon-Henry Gabrielle (Pr Boisson); (25) Lyon-Henry Gabrielle (Pr Eyssette, Dr Frenay); (26) Marseille-Clinique St-Martin (Dr ChapuisDucoffre); (27) Marseille-Valmante (Drs Benezet et Allovon); (28) Montpellier-Propara (Dr O'Hanna, Dr RouaysMabit); (29) Mulhouse (Dr Jacob-Chia); (30) Nantes (Pr Mathé, Drs Perrouin-Verbe et Rome); (31) Neufmoutiersen-Brie-Les Lycéens (Dr François); (32) Pen-Bron (Dr Tanguy); (33) Rennes Beaulieu (Pr Brissot, Dr Gallien); (34) Saint-Hilaire du Touvet (Dr Pauget); and (35) Strasbourg (Dr Pinelli).

\section{References}

1 DeVivo MJ et al. Trends in spinal cord injury demographics and treatment outcomes between 1973 and 1986. Arch Phys Med Rehabil 1992; 73: 424-430.

2 Frankel HL et al. Long-term survival in spinal cord injury: a fifty year investigation. Spinal Cord 1998; 36: 266-274.

3 Shingu $\mathrm{H}$ et al. A nation-wide epidemiological survey of spinal cord injuries in Japan from January 1990 to December 1992. Paraplegia 1995; 33: $183-188$.

4 DeVivo MJ, Richards JS, Stover SL, Go BK. Spinal cord injury rehabilitation adds life to years. West J Med 1991; 154: 602-606.

5 Krause JS. Longitudinal changes in adjustment after spinal cord injury : A 15-year study. Arch Phys Med Rehabil 1992; 73: $564-$ 568.

6 Levi R, Hultling C, Nash M, Seiger A. The Stockholm Spinal Cord Injury Study : 1. Medical problems in a regional SCI population. Paraplegia 1995; 33: $308-315$.

7 McColl MA, Walker J, Stirling P. Expectations of life and health among spinal cord injured adults. Spinal Cord 1997; 35: 818-828.

8 Hartkopp A, Brønnum-Hansen H, Seidenschnur AM, BieringSørensen F. Survival and cause of death after traumatic spinal cord injury. A long-term epidemiological survey from Denmark. Spinal Cord 1997; 35: $76-85$.

9 Stover SL, Fine PR. Spinal cord injury: the facts and figures. Birmingham (AL) : University of Alabama at Birmingham, 1986.

10 Daverat $\mathrm{P}$ et al. The long-term outcome in 149 patients with spinal cord injury. Paraplegia 1995; 33: 665-668.

11 Barbin JM et al. Enquête sur les conditions de vie de 291 blessés médullaires de retour à domicile. Ann Réadaptation Méd Phys 1998; 41: 35-40.

12 Whiteneck GG et al. Mortality, morbidity, and psychosocial outcomes of persons with spinal cord injury injured more than 20 years ago. Paraplegia 1992; 30: 617-630.

13 DeVivo MJ, Stover SL, Black KJ. Prognostic factors for 12-year survival after spinal cord injury. Arch Phys Med Rehabil 1992; 73: $156-162$.

14 DeVivo MJ. Causes and costs of spinal cord injury in the United States. Spinal Cord 1997; 35: 809-813.

15 Biering-Sørensen F, Pedersen V, Clausen S. Epidemiology of spinal cord lesions in Denmark. Paraplegia 1990; 28: 105-118.

16 Minaire P, Demolin P, Bourret J. Life expectancy following spinal cord injury: a ten-year survey in the Rhône-Alpes region, France, 1969-1980. Paraplegia 1983; 21: $11-15$.

17 Daverat P, Dartigues J-F, Mazaux J-M, Barat M. Initial factors predicting functional performance in patients with traumatic tetraplegia. Paraplegia 1990; 28: 414-419. 
18 Ravaud J-F et al. The Tetrafigap Survey on the long-term outcome of tetraplegic spinal cord injured individuals: Part I. Protocol and methodology. Spinal Cord 1998; 36: 117-124.

19 Krause JS. Adjustment after spinal cord injury: a 9-year longitudinal study. Arch Phys Med Rehabil 1997; 78: 651-657.

20 Minaire $\mathrm{P}$ et al. Epidemiology of spinal cord injury in the RhôneAlpes Region, France, 1970-75. Paraplegia 1978; 16: $76-87$.
21 Maharaj JC. Epidemiology of spinal cord paralysis in FIJI: 1985 - 1994. Spinal Cord 1996; 34: 549 - 559.

22 Lin K, Chuang C, Kao M. Quality of life of spinal cord injured patients in Taiwan: a subgroup study. Spinal Cord 1997; 35: 841 849. 